\title{
Comparative assessment of microbiological safety of fresh and parboiled Engraulicypris sardella (Usipa) from selected selling points in the city of Mzuzu, Malawi
}

\begin{abstract}
This study assessed the microbiological safety of fresh and parboiled E. Sardella from selected selling points in the city of Mzuzu, Malawi. Samples were collected during the cold, dry and rainy seasons and the total plate count (TPC) was determined in CFU/g. The isolated colonies were sub cultured by streak method on selective and differential media to ascertain bacteria species. Bacteria species were subjected to confirmatory tests (gram-staining, carbohydrates, coagulase, catalase and indole) and motility tests. Counts of fresh samples were comparably higher than those of the parboiled samples during all the three seasons. During the cold season, the mean bacterial load of fresh E. Sardella was $2.26 \times 10^{5} \mathrm{CFU} / \mathrm{g}$ and parboiled was $1.85 \times 10^{5} \mathrm{CFU} / \mathrm{g}$, records of dry season fresh samples yielded $1.50 \times 10^{5} \mathrm{CFU} / \mathrm{g}$ and parboiled samples were $1.05 \times 10^{5} \mathrm{CFU} / \mathrm{g}$ and finally, the rainy season fresh samples produced $2.41 \times 10^{5} \mathrm{CFU} / \mathrm{g}$ and parboiled $1.86 \times 10^{5} \mathrm{CFU} / \mathrm{g}$. The bacteria species identified were: Proteus, Enterobacter, Klebsiella, Pseudomonas, E. coli, Enterococcus, Shigella, Salmonella, Staphylococcus aureus, Staphylococcus epidermis, Vibrio cholerae and Vibrio parahaemolyticus. As expected, the moisture content influenced the growth of bacteria in fish: for fresh E. Sardella, it was $17.40 \pm 0.19 \%, 15.52 \pm 0.22 \%$ and $16.21 \pm 0.31 \%$ during cold, dry and rainy seasons respectively. Regarding parboiled samples, the moisture content was $10.43 \pm 0.03 \%, 9.55 \pm 0.38 \%$ and $9.36 \pm 0.99 \%$ for cold dry and rainy seasons, respectively. Statistically, the paired t- test showed significant differences in bacterial load among seasons and between treatments. It was observed that, the parboiling process reduced microbial load but poor hygiene, handling, storage and method of preservation influenced the load. Therefore, controlled temperatures, careful processing methods, proper storage and preservation are recommended to reduce incidence of microorganisms in fish.
\end{abstract}

Keywords: seasons, bacterial load, bacterial species, moisture content, temperature, processing and preservation
Volume 6 Issue 4 - 2018

\author{
Charles Watchipa Mgwede, Orton Msiska, \\ Fanuel Kapute \\ Mzuzu University, Malawi
}

Correspondence: Charles Watchipa Mgwede, Mzuzu University, Private Bag 20I, Luwinga, Mzuzu, Malawi, Email cwatchipa@gmail.com

Received: June 29, 2018 | Published: July 24, 2018

\section{Introduction}

Due to the soft tissues due to the aquatic environment, fish are vulnerable to microbial contamination. ${ }^{1}$ The microbial load is a reflection of quality of the processing methods as well as the hygiene of the processors and sellers. ${ }^{2}$ According to Kapute, ${ }^{3}$ fish processing methods and quality control in Malawi are poor and have remained traditional, thereby resulting in high post-harvest fish loss. SADC ${ }^{4}$ reported that Malawi produced 144,315tons of fish annually from capture fisheries and 5,000tons from aquaculture. According to Banda et al., ${ }^{5}$ fish provides about $30 \%$ of dietary protein in Malawi. However, researchers have estimated that about $40 \%$ of the catch is lost to spoilage, ${ }^{4}$ although some of this is consumed by humans, albeit at risks to their health. When fish die the defence system collapses resulting in microbial attack. ${ }^{6}$ The spoilage depends on several factors such as nutrient content, $\mathrm{pH}$, water activity, relative humidity, temperature, gaseous exchange, implicit and microbial factors. ${ }^{7}$ Therefore, rough handling and any bruising will result in more spoilage as damaged fish would easily be attacked by the microbes. Quick perishability has been a problem in fish preservation. ${ }^{8,9}$ Jakhar et al. ${ }^{10}$ states that sometimes even the preserved fish like the dried fish have higher bacterial load than the fresh fish due to high humidity compounded by unhygienic processing, handling and poor storage. During the rainy season, humidity levels are usually high and the drying processes are compromised resulting in spoilage by microbial organisms. ${ }^{8}$ Engraulicypris sardella is an endemic species in Lake Malawi and one way of prolonging its shelf life that has been employed over many years is by parboiling. This process allows for lengthening preservation by reducing moisture and partially cooking, which affects the growth of microorganisms. Parboiling process involves heating followed by sun drying. This form of processing sometimes provides little protection against microorganisms because of the nature of hygienic standards during processing, handling, storage and little caring given to selling benches at the open markets. There is no study which has been conducted to quantify the total bacterial load in fresh and parboiled $E$. Sardella with respect to seasons. It is against this background that this study was conducted to assess the safety to human consumption of fresh and parboiled E. Sardella during cold, dry and rainy seasons and also to identify some of the common bacteria species that contaminate the fish during the handling, processing and marketing processes. This study will also serve to inform more safety conscious consumers and the market acceptability of exported fish. 


\section{Methods and materials}

These generally conformed to standard methods as outlined by AOAC. ${ }^{11}$

\section{Sample collection for analysis}

Twenty samples for each of the fresh and parboiled E. Sardella were collected from different markets around the city of Mzuzu, Malawi. The samples were put in a cooler box and taken to the Malawi Polytechnic and Chancellor College at University of Malawi (UNIMA) laboratories for microbiological analysis (Figures 1-4).

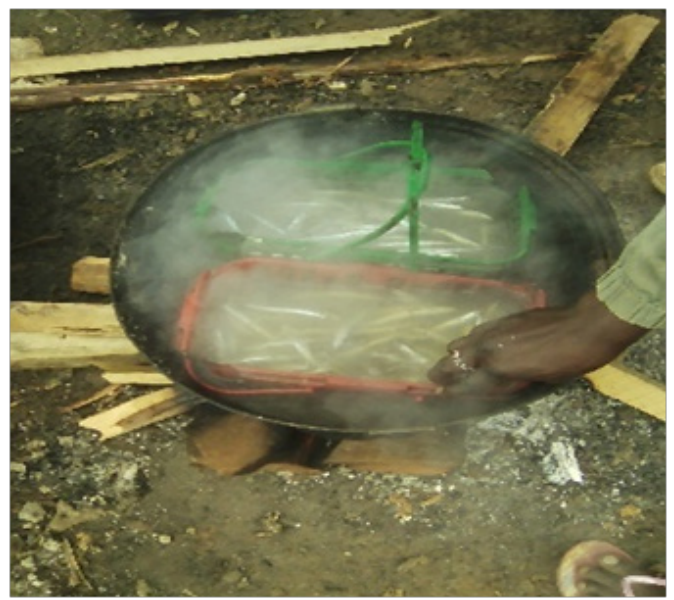

Figure I Process of parboiling.

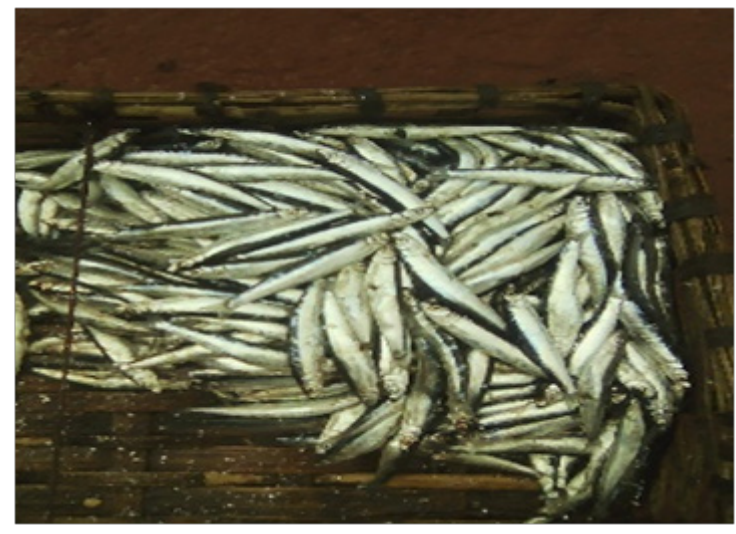

Figure 2 Fresh E. sardella in bamboo basket.

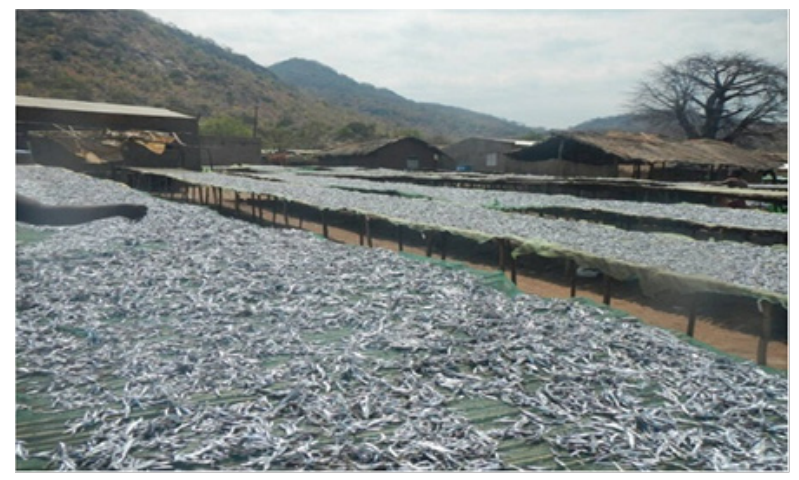

Figure 3 Drying parboiled E. sardella on bamboo benches.

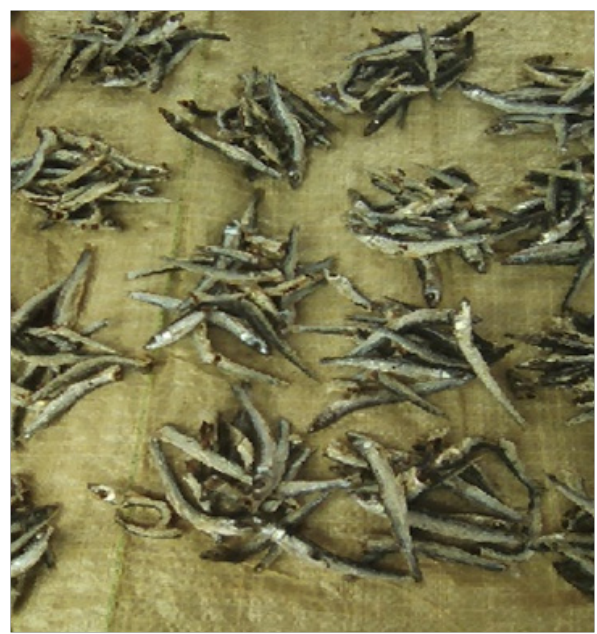

Figure 4 Parboiled E. sardella at the market.

\section{Microbial load determination}

The media used in this study include: Nutrient agar, MH, MCA, XLD, SSA, MSA and TCBS. Media preparation was done according to Mungeyi \& Msiska $^{12}$ and Kapute et al. ${ }^{13}$

\section{Total bacterial count}

Fish samples were analyzed for total plate count (TPC) following the method outlined by Obi \& Krakowiaka. ${ }^{14}$ A sub-sample of $1 \mathrm{ml}$ of each sample was put in sterile de-ionized water and serial dilutions $\left(10^{-1}\right.$ to $\left.10^{-5}\right)$ were prepared for total plate count. One (1)ml of appropriate dilutions were seeded on plate agar using spread plate method and then incubated for $18-24$ hours at $37^{\circ} \mathrm{C}$. After incubation, the number of colony forming units per gram $(\mathrm{CFU} / \mathrm{g})$ for each sample was calculated by multiplying the average number of colonies and the appropriate dilution factor.

\section{Isolation and identification}

Using microscopy, the plates for both treatments were examined and colonies present were isolated by size, shape, and colour and sub-cultured on selective and differential media by streak method. The plates were incubated at $37^{\circ} \mathrm{C}$ for $18-24$ hours. After incubation different types of bacteria were identified using morphological attributes and colour.

\section{Gram staining}

Gram staining was done to differentiate the gram reaction, sizes, shapes and cell arrangement according to Collins et al. ${ }^{15}$

\section{Biochemical tests}

The identified bacteria were subjected to confirmatory tests to ascertain the bacteria species. The following biochemical tests were done: Carbohydrate tests (sucrose, glucose, fructose, lactose and mannitol), catalase test, coagulase test and indole test.

\section{Motility test}

The bacteria cultured on the selective and differential media were also subjected to a motility test to confirm the bacteria species.

The means of colony forming units per season were calculated by 
dividing the multiplication of $\mathrm{CFU} / \mathrm{ml}$ and average number of colonies by summation of average number of colonies of the treatment.

\section{Moisture determination}

The moisture content of the samples was determined using the AOAC official method for analysis ${ }^{11}$ :

$$
\text { Moisture }=\frac{\text { Weight loss }}{\text { Original weight of sample }} \times 100 \%
$$

\section{Data analysis}

The data collected from the study was analyzed by paired t-test using SPSS statistical package version 16.0 at $5 \%$ level of significance.

\section{Results}

The microbial load was shown in Table 1. Comparison of the total bacterial load of the fresh and parboiled samples of E. Sardella showed that fresh samples had the highest total colony counts of $2.26 \times 10^{5} \mathrm{CFU} / \mathrm{g}, 1.50 \times 10^{5} \mathrm{CFU} / \mathrm{g}$ and $2.41 \times 10^{5} \mathrm{CFU} / \mathrm{g}$ during cold, dry and rainy seasons, respectively, while the parboiled samples had the lowest total colony counts of $1.85 \times 10^{5} \mathrm{CFU} / \mathrm{g}, 1.05 \times 10^{5} \mathrm{CFU} / \mathrm{g}$ and $1.86 \times 10^{5} \mathrm{CFU} / \mathrm{g}$ during cold, dry and rainy seasons, respectively. The trend indicated that the parboiled samples had reduced bacterial load during all seasons. The total bacterial loads between fresh and parboiled samples were significantly different during the period of the study. Selective and differential media with the help of confirmatory biochemical tests indicate which species of bacteria were present as shown in Table 2. The bacteria species were identified in both the fresh and the parboiled treatments for all the three seasons of the study.
Table I Microbial mean colony forming units $(\mathrm{CFU}) / \mathrm{g}$ during the three seasons

\begin{tabular}{lll}
\hline Season & Fresh Sample & Parboiled Sample \\
\hline Cold & $2.26 \times 10^{5}$ & $1.85 \times 10^{5}$ \\
Dry & $1.51 \times 10^{5}$ & $1.05 \times 10^{5}$ \\
Rainy & $2.41 \times 10^{5}$ & $1.86 \times 10^{5}$
\end{tabular}

The round shaped (cocci) bacteria observed in the study include: Enterococcus, Staphylococcus aureus and Staphylococcus epidermis. The other bacteria were rod shaped. The Gram staining reaction revealed that the cocci bacteria identified in the study were Gram positive. While only Enterococcus showed negative results for catalase test and only Staphylococcus aureus showed positive results for coagulase test, Proteus, Escherichia coli, Vibrio cholerae and Vibrio parahaemolyticus reacted positively to indole test. Pseudomonas revealed that it did not use glucose, fructose, lactose, sucrose and mannitol as sources of energy for its metabolic activities. Staphylococcus aureus did not use glucose as its energy source. The results also indicated that Proteus, Klebsiella, Staphylococcus aureus and $V$. parahaemolyticus did not get energy from fructose and that Enterobacter, Klebsiella, E. coli, Entrococcus and Staphylococcus epidermis used lactose as source of energy. E. coli, Shigella and Salmonella also did not use sucrose as their source of energy. While other species used mannitol as source of energy, Proteus, Shigella and S. epidermis did not use mannitol as energy source. Out of the species isolated and identified in the study only Klebsiella, Enterococcus, Shigella and S. aureus were not motile.

Table 2 Biochemical tests and Microscopy of bacteria species for cold, dry and rainy seasons

\begin{tabular}{|c|c|c|c|c|c|c|c|c|c|c|c|}
\hline Bacteria type & Shape & Gram Reaction & Cat & Coal & Indol & Glu & Fru & Lac & Suc & Man & Mot \\
\hline Proteus & Rod & - & + & - & + & + & - & - & + & - & + \\
\hline Enterobacter & Rod & - & + & - & - & + & + & + & + & + & + \\
\hline Klebsiella & Rod & - & + & - & - & + & - & + & + & + & - \\
\hline Pseudomonas & Rod & - & + & - & - & - & - & - & - & - & + \\
\hline Escherichia coli & Rod & - & + & - & + & + & + & + & - & + & + \\
\hline Enterococcus & Cocci & + & - & - & - & + & + & + & + & + & - \\
\hline Shigella & Rod & - & + & - & - & + & + & - & - & - & - \\
\hline Salmonella & Rod & - & + & - & - & + & + & - & - & + & + \\
\hline S. aureus & Cocci & + & + & + & - & - & - & - & + & + & - \\
\hline Vibrio cholera & Rod & - & + & - & + & + & + & - & + & + & + \\
\hline Vibrio parahaemolyticus & Rod & - & + & - & + & + & - & - & + & + & + \\
\hline S. epidermis & Cocci & + & + & - & - & + & + & + & + & - & + \\
\hline
\end{tabular}

Cat, catalase; Coa, coagulase; Indol , indole; Glu, glucose; Fru, fructose; Lac, lactose; Suc, sucrose; Man, mannitol; Mot, motility. 
There was a connection between the moisture content and the microbial load. Table 3 shows the moisture content of the samples during the study period.

Table 3 Percent mean moisture content for fresh and parboiled E. sardella during the three seasons

\begin{tabular}{lll}
\hline Season & Fresh Sample & Parboiled Sample \\
\hline Cold & $17.40 \pm 0.19^{\mathrm{a}}$ & $10.43 \pm 0.03^{\mathrm{b}}$ \\
Dry & $15.52 \pm 0.22^{\mathrm{a}}$ & $9.55 \pm 0.38^{\mathrm{b}}$ \\
Rainy & $16.21 \pm 0.3 \mathrm{I}^{\mathrm{a}}$ & $9.36 \pm 0.99^{\mathrm{b}}$
\end{tabular}

The results showed that moisture content in fresh samples was higher than in the parboiled samples during all the seasons. Fresh samples registered $17.40 \pm 0.19 \%, 15.52 \pm 0.22 \%$ and $16.21 \pm 0.31 \%$ during cold, dry and rainy seasons. Parboiled samples registered $10.43 \pm 0.03 \%, 9.55 \pm 0.38 \%$ and $9.36 \pm 0.99 \%$ during cold, dry and rainy seasons, respectively. The results were significantly different for all the seasons between the two treatments $(<0.05)$.

\section{Discussion}

The microbial load of E. Sardella was higher in fresh than in parboiled samples during all the seasons of the study. Similarly, Oladipo \& Bankole ${ }^{16}$ reported the same trend in fresh and dried Clarias gariepinus and in the treatment of Oreochromis niloticus. Ahmed \& Eltegani $\mathrm{i}^{17}$ also reported similar observations. Ayeloja et al. ${ }^{18}$ observed a higher microbial load in fresh samples of Clarias gariepinus than in smoked and cooked samples. According to Christianah \& Fagade, ${ }^{19}$ the occurrence of microorganisms is supported by moisture content which facilitates growth and multiplication. Fish is an ideal substrate for growth and multiplication of the microorganisms because of the availability of appropriate nutrients and moisture. ${ }^{20}$ The results of the proximate composition of the study indicated that the fresh samples had higher moisture content than the parboiled samples during all the three seasons of the study. While it is obvious for moisture to be high in the fresh fish, Christianah \& Fagade ${ }^{19}$ reported that dried fish were able to absorb moisture from the environment, which would then support the growth and multiplication of the microorganisms. However, although low moisture content would suppress the microbial growth, some would still survive the dry environment for some time before they die, especially those that form spores. ${ }^{21}$ This could be the reason why the parboiled E. Sardella had some microbial load despite the heating and drying processes it underwent. The moisture content is directly associated with the microbial load such that growth is slowed down as the water content reduces. ${ }^{22}$ This confirms findings of Kumolu-Johnson \& Ndimele $^{23}$ that spoilage of fish caused by bacteria and enzymes could be reduced by reducing the moisture content through processes such as drying or smoking. Low moisture content slows bacterial growth and multiplication and boiling reduces bacterial load considerably. ${ }^{24}$ Therefore, the low total bacterial count in parboiled E. Sardella in the study may be attributed to low moisture content after drying and heating during processing. On the other hand, Yusuf \& Hamid ${ }^{25}$ attributed the difference in fish microbial load to differences in methods of processing, handling, storage and distribution. Christianah \& Fagade $^{19}$ also reported that fish became contaminated during display on the market stalls apart from the processing and handling. According to Surendran et al., ${ }^{26}$ the acceptable limit of bacterial load in fresh fish is $5 \times 10^{5} \mathrm{CFU} / \mathrm{g}$ at $37^{\circ} \mathrm{C}$ and that of dried fish is $1 \times 10^{5} \mathrm{CFU} / \mathrm{g}$ at $37^{\circ} \mathrm{C}$. Therefore, the results of this study for fresh samples were within the range of the maximum limit during all the three seasons while for the parboiled, the findings during dry season were within range. However, the findings for cold and rainy seasons for the parboiled treatment were slightly above the limit $\left(1 \times 10^{5} \mathrm{CFU} / \mathrm{g}\right.$ at $\left.37^{\circ} \mathrm{C}\right)$. The high levels of microbial load in fresh fish indicated that they are vulnerable to decomposition as compared to the dried fish at ambient temperatures. ${ }^{27}$

The mean total bacterial counts for rainy and cold seasons were higher than those of the dry season within the treatments of both the fresh and the parboiled E. Sardella in the study. This observation was in agreement with the findings of Abolagba \& Uwagbai ${ }^{6}$ who reported a higher mean total bacterial count during the rainy season than during the dry season due to high moisture during the rainy season because of high humidity. High moisture supports the growth and multiplication of bacteria. ${ }^{28}$ The results of the study, contradicted with the observations of Sulieman \& Mustafa ${ }^{27}$ who reported more microbial load in summer than in winter. However, the load for summer season ranged from $2.5 \times 10^{5} \mathrm{CFU} / \mathrm{g}$ to $5.1 \times 10^{6} \mathrm{CFU} / \mathrm{g}$ which was well above the load of the findings of the fresh E. Sardella during the dry season while the load for cold season ranged from $8.6 \times 10^{3} \mathrm{CFU} / \mathrm{g}$ to $2.2 \times 10^{6} \mathrm{CFU} / \mathrm{g}$ within which the load of $2.26 \times 10^{5} \mathrm{CFU} / \mathrm{g}$ for cold season of the study falls. Bacteria species that belong to the natural micro flora of fish are Pseudomonas and Vibrios and those present due to feacal contamination are Salmonella, Shigella, E. coli, and Staphylococcus aureus were isolated and identified in the study. The occurrence of some species of bacteria in the study was in accordance with the observations made by Kapute et al. ${ }^{13}$ and Ching' anda. ${ }^{29}$ While Islam et al. ${ }^{20}$ reported that heating that occurs during the dry season reduced the load of microorganisms, Ayeloja et al. ${ }^{18}$ observed high presence of E. coli, Staphylococcus aureus, Bacillus, Pseudomonas aerogenosa bacteria species in both fresh and smoked Clarias gariepinus. Species of Pseudomonas are psychrophilic and regarded as part of the natural micro flora of the fish. ${ }^{30}$ Therefore, after heating, Pseudomonas is expected to be absent in the dried fish. However, the study revealed that Pseudomonas was present in both fresh and dried E. Sardella samples during all the three seasons, confirming the observations of Kasozi et al. ${ }^{30}$ According to Lyhs, ${ }^{31}$ the presence of bacteria species such as Salmonella, Shigella, Staphylococcus aureus and E. coli was due to contamination. Additionally, Kasozi et al. ${ }^{30}$ attributed the presence of Pseudomonas to poor hygiene during processing and storage. This implies that processing methods of $E$. Sardella could not get rid of Pseudomonas completely despite the heating and drying in the sun. This could also be compounded by the poor storage facilities and poor means of transportation, confirming observations by Kapute. ${ }^{3}$ Contrary to the findings of the study, Ahmed \& Eltegani ${ }^{17}$ did not detect the presence of E.coli and Staphylococcus aureus in dried fish treatment but detected Salmonella in the fresh fish treatment. Vibrio species occur naturally in marine and freshwater environments and therefore are connected with food from freshwater sources like the fish. ${ }^{32,33}$ This could be the reason why Vibrios were present in both treatments during all the three seasons of the study. As indicated in the study, the microorganisms isolated are of public health implication, hazardous and injurious to humans if consumed.

\section{Conclusion and recommendations}

The results of the study revealed that the total bacterial count (TBC) of fresh E. Sardella was higher than that of the parboiled $E$. Sardella during all the three seasons. The study also indicated that 
the total bacterial count (TBC) in fresh and parboiled were highest during the rainy season, followed by the cold season and lastly the dry season. Process of drying in parboiled E. Sardella resulted in reduced load of microorganisms, hence guaranteeing some safety of the product. Therefore moisture as an index of perishability, favors the parboiled E. Sardella. The study also revealed that apart from psychrophilic species like Pseudomonas, which form part of the natural flora of bacteria in fish, other species of bacteria like Salmonella, Shigella, Staphylococcus aureus, E. coli were present due to poor hygiene and other sanitary practices during processing and storage. The study therefore recommends the need for proper hygienic conditions during processing, handling, distribution, packaging and storage of the fish and fish products. There is need also to keep fish at very low temperatures to retard the multiplication of the microorganisms along the supply chain. On the part of the processors, there is need for sanitation awareness campaigns to help reduce levels of contamination and improve the quality of the fish and their products. While it is recommended for relevant authorities to enforce improved quality and safety of the fish to members of the general public, it is also recommended for researchers to develop appropriate technologies for processing, handling, preservation and storage. There is need to popularize safe handling, processing and distribution methods to the general public through Mzuzu City, who should be aware of the findings for further community awareness. Finally, it is valuable to quantify the load of individual species of bacteria during different times of the year.

\section{Acknowledgements}

The authors express their sincere thanks to the technicians, Mr. J. Murowa and Mr. Adams and Members of staff of Fisheries and Aquatic Science Department, Mzuzu University for the support during the study.

\section{Conflict of interest}

The author declares that there is none of the conflicts.

\section{References}

1. Olayami FF, Raji AO, Adedayo MR. Microbiological quality of catfish (Clarias gariepinus) smoked with Nigerian Stored Products Research Institute (NSPRI) developed smoking kiln. International Journal of Microbiology. 2012;3(13):426-430.

2. Jeyasanta KI, Giftson H, Saritha K, et al. Studies on the nutritional and microbiological quality of smoked Tuna fish (Auxis thazard) in Tulicolin, South East Coast of India. International Journal of Food quality and Safety. 2015;1:28-38.

3. Kapute F. Fish quality and processing in Malawi: Responding to challenges through institutional capacity building. Iceland: The United Nations University; 2008

4. SADC. SADC protocol on fisheries: Focus on Malawi fisheries sector. SADC Fisheries Fact Sheet. 2016;1(3):1-10.

5. Banda M, Jamu D, Njaya F, et al. The chambo restoration strategic plan. World fish Centre Conference Proceedings; 2005.

6. Abolagba OJ, Uwagbai EC. A comparative analysis of the microbial load of smoke-dried fishes (Ethmalosa fimbriata and Pseudotolithus Elongatus) sold in Oba and Koko Markets in Edo and Delta States, Nigeria at Different Seasons. Australian Journal of Basic \& Applied Sciences. 2011;5(5):544-550.
7. Adam MR, Moss MO. Food Microbiology. 3rd ed. UK: Royal Society of Chemistry; 2008. p.1-478.

8. Okoro CC, Aboaba OO, Babajide OJ. Quality assessment of a Nigerian marine fish, Mullet (Liza falcipinnis) under different storage conditions. New York Science Journal. 2010;3(8): 21-28.

9. Dewi RS, Huda N, Ahmed R. Changes in the physiochemical properties, microstructure and sensory characteristics of Shark Dendeng using different drying methods. American Journal of Food Technology. 2011;6(2):149-157.

10. Jakhar JK, Kumar A, Vardia HK. Hygienic and nutritional quality of traditional dried and smoked fishes at Kawardha Fish Market (Chhattisgarh), India. The Bioscan. 2015;10(3):1099-1102.

11. AOAC. Official methods of analysis of association of analytical chemist 15th ed. Washington DC.1990.

12. Mungeyi P, Msiska OV. Incidences of Escherichia coli and Salmonella spp in processed hake from companies based at Walvis Bay, Namibia. Malawi Journal of Aquatic Fisheries. 2009;1:13-18.

13. Kapute F, Likongwe J, Kang'ombe J, et al. Quality assessment of fresh Lake Malawi Tilapia (chambo) collected from selected local and supermarkets in Malawi. International journal of Food Safety. 2012;14:113-121.

14. Obi SKC, Krakowiaka A. Theory and practice of food microbiology. 1983.

15. Collins CH, Lyne PM, Grande G. Collins and Lyne microbiological methods. 6th ed. UK: 1989. p. 1-465.

16. Oladipo IC, Bankole SO. Nutritional and microbial quality of fresh and dried Clarias gariepinus and Oreochromis niloticus. International Journal of Applied Microbiology and Biotechnology Research. 2013;1(1):1-6.

17. Ahmed SH, Eltegani IE. Effect of drying on microbial load of Clarias sp meat. International Journal of Biology, Pharmacy and Applied science. 2012;1(3):337-344

18. Ayeloja AA, George FOA, Obasa SO, et al. Effect of post-slaughter time intervals on the quality of the African catfish, Clarias gariepinus (Barchell, 1882). American Journal of Food Technology. 2011;6(9):790-797.

19. Christianah IA, Fagade DE. Mycological evaluation of smoked fish from the retail outlets in Ago-Inouye, Ogan states, Nigeria. Acta SATECH. 2010;3(2):65-66

20. Islam T, Ahmed S, Sultana A, et al. Nutritional and food quality assessment of dried fishes in Singra Upazila under Natore District of Bangladesh. Trends in fisheries Research. 2013;2(1):14-17.

21. Orael M, Motalebi AA, Hoseini E, et al. Effect of gamma irradiation and frozen storage on microbial quality of rainbow trout (Oncorhynchus mykiss) fillet. Iranian Journal of Fisheries Sciences. 2011;10:75-84.

22. Nketsia N, Tabiri J. Radiation decontamination and disinfestations of salted dried Tilapia fish (Koobi). Ghana Journal of Agricultural sciences. 2003;10:85-90.

23. Kumolu-Johnson CA, Ndimele PE. Effect of salting, brining and sun drying on the shelf life of Clarias gariepinus (Lacepede). Journal of Research and Review Sciences. 2001;2:21-25.

24. Chavan BR, Basu S, Kovale SR. Development of edible texturised dried fish granules from low-value fish croakers (Otolithus argentieus) and its storage characteristics. Chiang Mai University Journal of Natural Sciences. 2008;7(1):173-182.

25. Yusuf AM, Hamid TATA. Isolation and identification of bacteria in retailed smoked fish within Bauchi Metropolis. Journal of Pharmacy and Biological Sciences. 2012;3(1):1-5. 
26. Surendran P, Nirmala TK, Narayanannambiar V, et al. Laboratory manual on microbiological examination of sea food. CIFT. 2006:28-45.

27. Sulieman AM, Mustafa WA. Quality characteristics of dried fish obtained from Eldeim Area, Central Sudan. International Journal of Food Sciences and Nutrition Engineering. 2012;2(1):1-6.

28. Pathak N, Zofair SM, Mulye VB, et sal. Effects of drying process on biochemical and microbiological quality of horse mackerel fish (Megalaspis cordyla). International Journal of Pharmacy and Biological Sciences. 2014;5(1):1-6.

29. Ching'anda C. Prevalence of histamine and pathogenic microorganisms in fish consumed in rural Malawian households. MSc. Thesis, Michigan State University. 2013.
30. Kasozi N, Namulawa VT, Degu GI, et al. Bacteriological and physicochemical quality of traditionally dry- salted pebbly fish (Alestes baremoze) sold in different markets of west Nile region, Uganda. African Journal of Microbiology Research. 2016;10(27):1024-1030.

31. Lyhs U. Fishery products: Quality, safety and authenticity. UK: Wiley Blackwell; 2009.

32. Hervio-heath D, Colwell RR, Derrien A, et al. Occurrence of pathogenic Vibrios in coastal areas of France. Journal of Applied Microbiology. 2002;92(6):1123-1135.

33. El-Hadi NS, Radu CH, Chen C, et al. Prevalence of potentially pathogenic Vibrio species in the sea food marketed in Malaysia. Journal of Food Production. 2004;67(7):1469-1475. 